
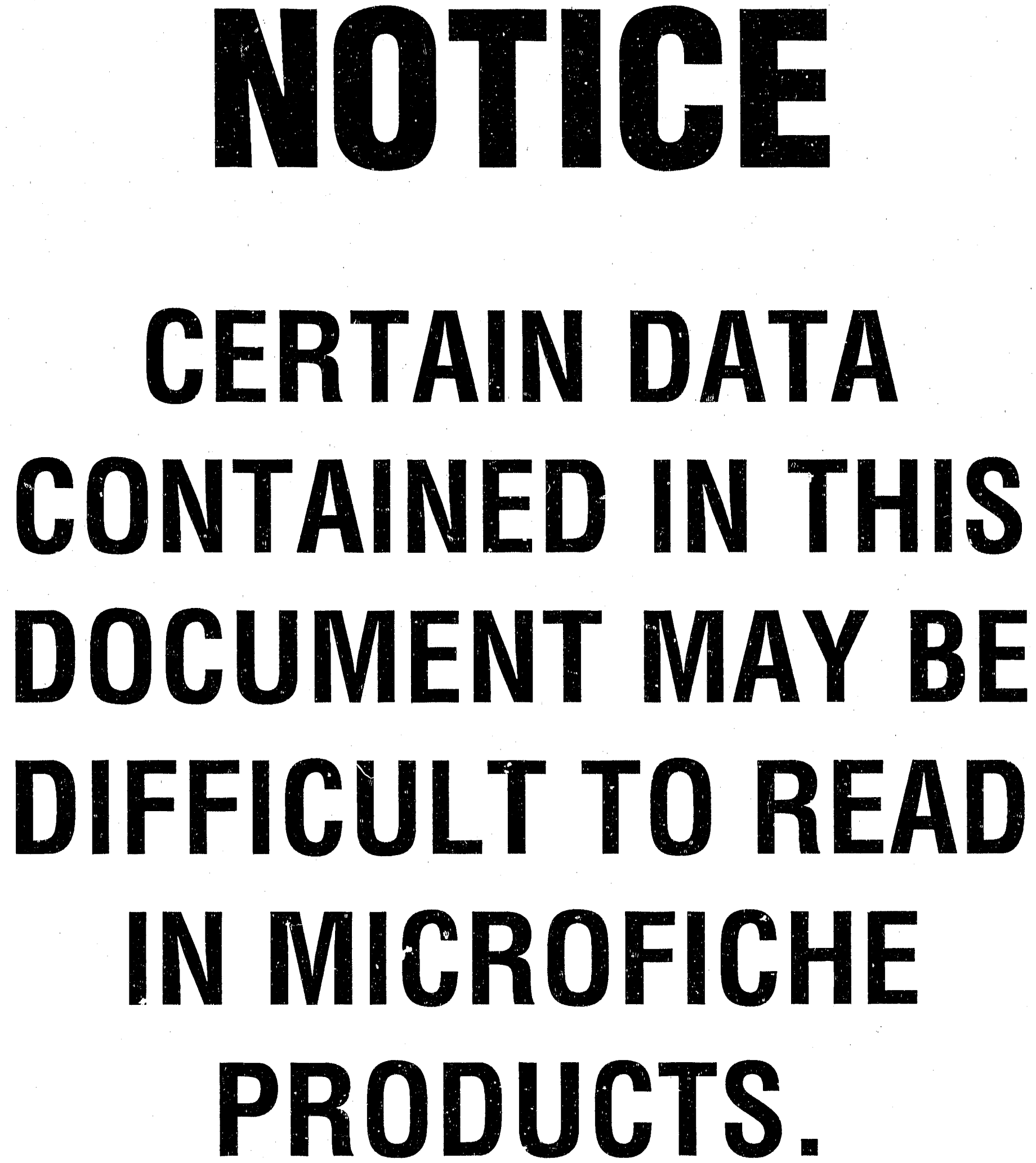
LA-UR-90- $\$ 315$

\title{
TITLE: HIGH POWER LINEAR ACCELERATORS FOR TRITIUM PRODUCTION AND TRANSMUTATION OF NUCLEAR WASTE
}

\author{
AUTHOR(S): G. P. Lawrence
}

$L A-T J R--90-3315$

DE9 1000187

\section{SUBMITTED TO: Eleventh International Conference on the Application of Accelerators in Research and Industry \\ November 5-8, 1990 \\ Denton, Texas}

\section{DISCLAIMER}

\begin{abstract}
This report was prepared as an account of work sponsored by an agency of the United States Government. Neither the United States Government nor any agency thereof, nor any of their employees, makes any warranty, express or implied, or assumes any legal liability or responsibility for the accuracy, completeness, or usefulness of any information, apparatus, product, or process disclosed, or represents that its use would not infringe privately owned rights. Reference herein to any specific commercial product, process, or service by trade name, trademark, manufacturer, or otherwise does not necessarily constitute or imply its endorsement, recommendation, or favoring by the United States Government or any agency thereof. The views and opinions of authors expressed herein do not necessarily state or reflect those of the United States Government or any agency thereof.
\end{abstract}

By acceptance of this article, the publisher recognizes that the U.S. Government retains a nonexclusive, royalty-free licerise to publish or reproduce the published form of this contribution, or to allow others to do so, for U.S. Government purposes.

The Los Alamos National Laboratory requests that the publisher identify this article as work performed under the auspices of the U.S. Department of Energy

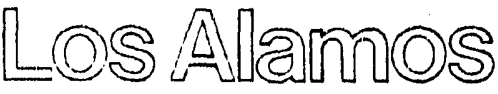

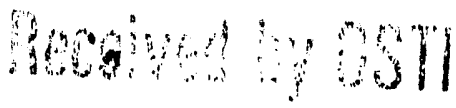




\title{
HIGH POWER LINEAR ACCELERATORS FOR TRITIUM PRODUCTION AND TRANSMUTATION OF NUCLEAR WASTE.*
}

\author{
G. P. LAWRENCE
}

Accelerator Technology Division, Los Alamos National Laboratory, Los Alamos, New Mexico 87545, USA

Proton linacs driving high-flux spallation neutron sources are being considered for transmutation of nuclear waste and production of tritium. Advances in high-current linac technology have provided a basis for the development of credible designs for the required accelerator, which has a nominal 1.6-GeV energy, and a 250-mA cw current . $\mathrm{A}$ beam with these parameters incident on a liquid lead-bismuth ( $\mathrm{Pb}-\mathrm{Bi}$ ) target can generate a thermal neutron flux of up to $5 \times 10^{16} \mathrm{n} / \mathrm{cm}^{2}-\mathrm{s}$ in a cylindrical blanket surrounding the spallation source. This high flux can produce tritium through the ${ }^{6} \mathrm{Li}(\mathrm{n}, \alpha) \mathrm{T}$ or ${ }^{3} \mathrm{He}(\mathrm{n}, \gamma) \mathrm{T}$ reactions, or can b'urn long-lived actinides and fission products from nuclear waste through capture and fission processes. In some system scenarios, waste actinides and/or other fissile materials in the blanket can produce sufficient fission energy to power the accelerator.

\section{Introduction}

Proton and deuteron accelerators driving high intensity neutron sources have been stuclied for more than 40 years for fissile-fuel breeding, fuel-elsment regeneration, and energy production from fertile materials, and to a lesser extent for witium production and nuclear waste burning (transmutation). ${ }^{1-3}$ A common thread of all previously considered concepts is that they employed a fast neutron spectrum $\left(10^{3}-10^{6} \mathrm{eV}\right)$, and a relatively lo'w neutron flux distributed over a large volume conversion region. Although the low price of uranium and the questionable future of commercial nuclear power has eliminated near-term interest in electronuclear fuel production and enrichment, tritium production and nuclear waste transmutation are in a different category. They address critical national needs that are not dominated exclusively by economic considerations. 
Tritium, an important ingredient in nuclear weapons, decays at the rate of $5.5 \%$ per year to ${ }^{3} \mathrm{He}$ and must be continuously replenished to maintain the effectiveness of the US nuclear defense. Los Alamos and Brookhaven recently proposed accelerator production of tritium (APT) ${ }^{4,5}$ to the DOE as a contingency production technology that should be developed in case implementation of the New Production Reactor (NPR) meets institutional obstacles. The APT design was sized for the same production capacity as the NPR, requiring a $1.6-\mathrm{GeV} \mathrm{cw}$ if linac delivering a $250-\mathrm{mA}$ proton beam to a target composed of a matrix of $\mathrm{Pb}$ and $\mathrm{Li}-\mathrm{Al}$ pins. A $75 \%$ plant availability was assumed. Each proton produces about 45 neutrons in the $\mathrm{Pb}$ by spallation and nuclear evaporation. The neutrons produce tritium via the ${ }^{6} \mathrm{Li}(\mathrm{n}, \alpha) \mathrm{T}$ reaction, and the tritium is extracted at intervals by chemical processing of the $\mathrm{Li}-\mathrm{Al}$ pins. The electric power required to generate the $400-\mathrm{MW}$ proton beam is $>900 \mathrm{MWe}$. The APT concept has attractive environment, safety, and health features, since there is no fissile material in the target. A complete reference design for the accelerator, beam transport; and target was developed in 1989 and reviewed by the Energy Research Advisory Board (ERAB). In their report to DOE, the ERAB stated that the accelerator design was technically sound and could be built after a suitable development program that would include an integrated front-end cw high-power demonstration. They also noted that the requirement for a large block of electric power is a major concern.

\section{Reference Accelerator Configuration}

The linac design developed for APT can be taken as representative of the class of machines needed for both tritium production and waste transmutation, although lower currents than $250-\mathrm{mA}$ are indicated in some transmutation schemes. Figure 1 shows the reference accelerrito configuration, which consists of a $2-\mathrm{km}-\mathrm{long}, 700-\mathrm{MHz}$, coupledcavity linac (CCL), injected at $20 \mathrm{MeV}$ by a funneled beam-launching system. The beam launcher is made up of two $100-\mathrm{keV}$, two $350-\mathrm{MHz}$ radiofrequency quadrupoles (RFQs) providing $125-\mathrm{mA}$ proton outputs at $2.5 \mathrm{MeV}$, and two $350-\mathrm{MHz}$ DTLs accelerating beams to $20 \mathrm{MeV}$. Table 1 summarizes the principal parameters of the accelerator. Reference 7 provides cietails on parameter selection, beam dynamics considerations, and the simulations used to predict beam performance. The APT linac was designed within a conservative framework, with the overall philosphy being that the low- $\beta$ beam launcher should be optimized to prepare a low-emittance, high-current beam with little halo, and the $\mathrm{CCL}$ parameters should be selected to assure very low beam loss while maintaining high rf efficiency. 


\section{Beam Dynamics}

Initial (unoptimized) physics designs and parameter selections were worked out for the separate segments of the linac using a uniform-charge ellipsoidal beam model. A complete end-to-end beam simulation was executed for this design using the code PARMTEQ for the RFQ, PARMILA for the DTL and funnel, and CCLDYN for the CCL. The initial 7500-particle distribution at the RFQ entrance was characterized by matched Gaussians in the transverse phase-space planes, and zero-energy spread in the longitudinal plane. A large mismatch was deliberately introduced between the RFQ and the DTL to provide a non-idealized calculation.

Although the average current in the APT CCL is very large, 250 times that of the highest power existing linac (LAMPF), the charge per bunch is only 4.5 times greater in APT than in the LAMPF CCL, because the duty factor is 1.0 and every rf bucket contains protons. This greater charge density is easily compensated by stronger transverse focusing, achieved by a high quadrupole linear density ( 4 times LAMPF).

Simulation results are shown in Fig. 2 which represents the 1.6-GeV output distributions in $x-y$ space and longitudinal phase space. The $x-y$ plot also shows the beam pipe boundary and the $\Delta \mathrm{W}-\phi$ plot shows the longitudinal acceptance (separatrix). In both transverse and longitudinal space the beam occupies a much smaller region than the acceptance. The CCL apertures were selected to provide an effective ratio of acceptance aperture to rms beam size ranging from 14 to 22 , a much larger factor than has been used in lower power linacs (6.3 for LAMPF). Simulations and extrapolations from LAMPF operating experience indicate that this large ratio will assure the extremely low fractional beam losses needed $\left(<1 \times 10^{-8}\right)$ to achieve "hands-on" maintenance of the accelerator, an important criterion for operability. Because of the high beam loading ( $78 \%$ in the $\mathrm{CCL}$ ) the large accelerating structure aperture has little effect on if efficiency.

High-order deflecting modes in the accelerating structure that might cause beam breakup were investigated and found not to be a problem for APT. Even though the current is large and the accelerator is long, the particle $\beta$ changes sufficiently fast that coherent transverse effects cannot not build up. 


\section{Machine Design}

The low- $\beta$ bearn launcher design is very different from the front end of earliergeneration linacs, and employs a decade's advances in the technology of high-current low- $\beta$ proton linacs. These advances, stimulated partly by the neutral particle beam (NPB) program, include: 1) RFQs replacing high-yoltage dc injectors to provide major bearn handling improvements in the first accelerating stage; 2 ) funneling which permits current doubling with no emittance penalty; 3 ) higher accelerating-structure frequencies and strong focusing for transverse emittance preservation; and 4) ramped accelerating gradients for longitudinal emittance preservation.

The ion source choice is between a mulki-aperture duoPIGatron or an ECR source. Both should be capable of producing the needed 140-mA current within the desired emittance, but need further development. Each RFQ carries $125 \mathrm{~mA}$, but has been conservatively designed for a current limit of $250 \mathrm{~mA}$. With a vane geometry having a constant radius of curvature, a peak surface field of $33 \mathrm{MV} / \mathrm{m}$ is expected (1.8 Kilpatrick). Each unit is driven by a single 1-MW 350-MHz cw klystron. Four quadrupoles and two if bunchers match the RFQ output into the DTL.

The DTLs use a FODO focusing lattice of radiation-hard electromagnet (EM) quadrupoles in the drift tubes. A $2 \beta \lambda$ cell provides sufficient length for these quads, which require a integral G.dl of $2.94 \mathrm{~T}$ to give a (zero current) phase advance per cell of $70^{\circ}$. The DTLs are configured in 5 tanks, each of which is driven by a $350-\mathrm{MHz} 1-\mathrm{MW}$ klystron. Permanent magnets were consciously avoided in the design because of the potential for neutron darnage. Given this decision, the mechanical limitations for a viable EM quad constrained the upper frequency limit to about $400 \mathrm{MHz}$, leading to a natural frequency choice of $350 \mathrm{MHz}$, where a commercially manufactured 1-MW cw klystron is available.

Funneling takes place at $20 \mathrm{MeV}$, using a design similar to that tested recently in Los Alamos. The two $125-\mathrm{mA}, 350-\mathrm{MHz}$ bunch trains are combined into a $250-\mathrm{mA}, 700-\mathrm{MHz}$ bunch train that is then accelerated by the CCL. EM quads are used except for two locations where geometrical constraints intervene. While starting the CCL structure at as low an energy as $20 \mathrm{MeV}$ is unconventional, the overall if efficiency penalty is minimal because of the dominant effect of the high- $\beta$ CCL; this choice allows elimination of a 700 $M \mathrm{H} z \mathrm{DT}$, which would need permanent magnets in the drift tubes. 
The CCL is subdivided into 7 separate sections, each of which is made up of sequences of lattice units. Each lattice unit is composed of an multicell coupled-cavity accelerating module, a quadrupole, and a beam diagnostic, with the number of coupled cells increasing from 2 in the lowest- $\beta$ section to 10 in the highest- $\beta$ section. Figure 3 shows an 8-cell unit. Short tanks with a singlet FODO quadrupole lattice provides high focusing strength per unit length to ke«p the rms beam size small. The transverse phase advance is held constant at $70^{\circ}$ per focusing period. Cavity parameters are optimized within each of the CCL sections to maximize the transit time. Cavity modules are bridged together in numbers requiring 1-MW of of input power per station. A new 1-MW cw 700$\mathrm{MHz}$ klystron is needed for the $\mathrm{CCL}$, which requires about 470 such tubes. Assuming a klystron dc-to-rf efficiency of 0.67 , the overall ac-to-beam power efficiency is estimated as about 0.47 . The average "real-estate" accelerating gradient is $1 \mathrm{MV} / \mathrm{m}$, a value near a broad minimum in projected lifetime costs. The design is driven to this low gradient because of the dominating effects of if system capital and operating costs. Thermal calculations show that the CCL structures can be easily cooled at this gradient in cw operation even at the low- $\beta$ end, where the structure-average gradient reaches $2.5 \mathrm{MV} / \mathrm{m}$.

The CCL geometrical layout is similar to LAMPF, with features borrowed from the design of the SNQ linac. ${ }^{8}$ The side-coupled linac is in a tunnel buried below $10-15 \mathrm{~m}$ of earth shielding. Klystrons, magnet power supplies, and instrumentation are located in a gallery above the linac that is accessible during operation. A non-occupation auxiliary tunnel alongside the linac allows shielding of radiation-sensitive equipment that must be located near the accelerator.

The beam is transported (in the initial APT concept) to one of two alternate tritium production targets by the high-energy beam transport system pictured in Fig. 4 . The HEBT includes an achromatic bend whose momentum bandwidth is $\pm 2 \%$, and terminates in a nonlinear optical expander that produces a nearly uniform $4 \mathrm{~m} \times 8 \mathrm{~m}$ rectangular beam distribution at the target face. 9

\section{Accelerator Technical Issues and Technology Base}

The major technical concerns for a high-power proton linac are: 1) beam-loss activation of machine components, which threatens hands-on maintainability; 2) machine damage from misdirection of the high-power beam; 3) improvement of $\mathrm{rf}$ system efficiency 
and reduction of rf-system unit capital costs; and 4) reliability and longevity of components needed to achieve a $75 \%$ plant factor. Accelerator technology improvements and advances in understanding of high-current beam behavior have provided much higher confidence than was possible in the late 70 s that a machine of the APT power level can be built and operated. The reference design for APT addressea the technical issues poirit by point, and includes end-to-end beam simulations with "realistic" matching errors, a machine configuration layout, preliminary engineering analysis of critical components (DTL quads), selection of components to match availability in the existing technology base (klystrons, ion sources), an analysis of off-normal accelerator conditions and beam/target safety arrangements, and a cost and optimization model to confirm parameter choices. The design codes have been benchmarked in the relevant energy and charge-density regimes by simulation of high-current behavior on the NPB Accelerator Test Stand at Los Alamos, and by an end-to-end simulation of LAMPF ${ }^{10}$ that confirms measured emittance values as well as beam loss locations and rough magnitudes.

A number of accelerator systems have already operated at or near APT-level parameter values. A $267-\mathrm{MHz}$ proton $\mathrm{RFQ}$ at $\mathrm{CRNL}$ has operated at $75 \mathrm{~mA}$, cw. Peak $\left(\mathrm{H}^{-}\right)$ currents of $100 \mathrm{~mA}$ have been demonstrated in a $7-\mathrm{MeV}$ ramped-gradient $425-\mathrm{MHz} \mathrm{DTL}$ at Los Alamos, and an 80-mA cw D- DTL is being built as part of the NPB program. Beam funneling in the relevant current and frequency range has been successfully demonstrated at Los Alamos. High power (0.5 - 1.0 MW) cw klystrons are available at several frequencies, including $352 \mathrm{MHz}, 500 \mathrm{MHz}$, and $1000 \mathrm{MHz}$. Some have dc-rf efficiencies close to 0.70 , and manufacturers believe that further efficiency improvements are possible.

Experience with existing linacs that have operated for years with high availability as multi-program research factories has provided a strong foundation for making extrapolations to the APT performance regime. Because of its high average current, operational experience at LAMPF is especially relevant, particularly in addressing the important beam-loss issue. For most of the CCL length, LAMPF beam losses are estimated to be $<0.2 \mathrm{nA} / \mathrm{m}$, and radiation levels after shutdown are compatible with unlimited-access hands-on maintenace at nearly all locations. Given the much larger aperture-to-beam-size ratio in the APT CCL and the higher quality input beam, we are able to project high confidence of contact maintainability even though average currents are two orders of magnitude higher. Klystron longevity has also been addressed by LAMPF operating statictics. Typical lifetime of the 1.25-MW peak-power $805-\mathrm{MHz}$ klystrons (up 
to $12 \%$ duty factor) has been $>50,000$ hours, with many tubes having operated for $>$ 80,000 hours.

Even though the expanding technology base now provides high confidence in the buildability of an APT-class accelerator, a cw high power example does not exist. In order to firmly establish an engineering basis for the design, it will be necessary to carry out a full-power cw front end demonstration, up to about $40 \mathrm{MeV}$.

\section{Neutron Production and Applications}

A $250-\mathrm{mA}, 1.6-\mathrm{GeV}$ proton beam incident on an appropriate spallation target generates about $10^{20}$ primary neutrons per second. After suitable moderation, these neutrons can be used in various target/blanket configurations to produce tritium through the ${ }^{6} \mathrm{Li}(\mathrm{n}, \alpha) \mathrm{T}$ or ${ }^{3} \mathrm{He}(\mathrm{n}, \gamma) \mathrm{T}$ reactions, or to burn long-lived actinides and fission products from nuclear waste through capture and fission processes. Initial studies of a lead-bismuth eutectic target surrounded by a cylindrical $\mathrm{D}_{2} \mathrm{O}$ moderator show that a thermal neutron flux $>2 \times 10^{16} \mathrm{n} / \mathrm{cm}^{2}-\mathrm{s}$ is achievable in a relatively large useful working region. Previous accelerator-based transmutation schemes have required a fast neutron spectrum in the conversion blanket. With thermal neutron fluxes in the $10^{16} \mathrm{n} / \mathrm{cm}^{2}-\mathrm{s}$ range (100 times greater than in standard thermal reactor designs), significant technical advances are possible. The higher actinides (such as ${ }^{237} \mathrm{~Np}$ ) are converted by neutron capture to daughter products that are fissioned rapidly by a second neutron interaction before they can decay to non-fissile isotopes. High fluxes of neutrons at thermal energies (where cross sections are large) also permit rapid conversion of long-lived fission products such as ${ }^{99} \mathrm{Tc}$ and ${ }^{127} \mathrm{I}$ to stable isotopes. These processes are shown schematically in Fig. 5. Shorter-lived species, such as ${ }^{90} \mathrm{Sr}$ and ${ }^{137} \mathrm{Cs}$, can also be converted at rates faster than their natural decay.

It is becoming clear that the present plan for disposal of defense and commercial highlevel nuclear waste, namely vitrification and long-term ( $10^{4}$ to $10^{5}$ years) storage in geologic repositories, is meeting increasing and deep-seated public skepticism and resistance. Transmutation, while not eliminating the need for short-term storage sites, may offer a way out of this dilemma. Taken together with appropriate chemical processing, there appears to be good potential that a small number of accelerator-driven thermal-neutron transmuters could form the key ingredient in a waste-management system that can destroy accumulated high-level defense wastes within timescales like a human lifespan. 
A transmutation concept currently being studied at Los Alamos consists of a 1.6-GeV, $250-\mathrm{mA}$ proton beam incident vertically on a $\mathrm{Pb}-\mathrm{Bi}$ target surrounded by a $\mathrm{D}_{2} \mathrm{O}$ moderated blanket, in which the material to be transmuted is carried in a dilute molten fluoride salt solution. The salt flows continuously in a loop at high temperature, using technology similar to that developed at ORNL years ago for the experimental molten salt reactor program. Higher actinides or $\mathrm{Pu}$ in the salt multiply the spallation neutron flux, producing sufficient fission power to run the accelerator. Advanced continuous fluoride chemical partitioning and processing methods appear to be capable of separating stable products from material that is recycled through the transmuter. Two-dimensional neutron transport calculations for an unoptimized target-blanket geometry show that a single $250 \mathrm{~mA}$ facility could transmute waste actinides and fission products at a rate of $500 \mathrm{~kg} /$ year. Given present inventory levels, accumulated wastes at defense production sites could be converted in 20 to 30 years. While these numbers show what can be done, this first calculational model is far from ideal, with about $50 \%$ of the accelerator-produced neutrons being absorbed in structural materials. Very general neutron economy arguments applied to similar systems show that the potential for performance optiimization is large. If, for example, a $13 \%$ neutron loss is assumed (consistent with molten salt reactor experience), then the beam current required to attain similar performance is much lower, and we could expect $500 \mathrm{~kg} / \mathrm{yr}$ transmutation rates with a $30-\mathrm{mA}$ accelerator.

Using this neutron economy picture, one can show that a single APT-class accelerator can burn the waste discharge of about eleven $1000 \mathrm{MWe}$ light-water reactors while providing enough power to run itself. Using the high temperature molten salt concept, overall thermal-electric efficiencies of about $30 \%$ appear feasible, if the accelerator-driven system is used to generate power from ${ }^{232}$ Th or ${ }^{238} \mathrm{U}$ fertile material feed, and enough neutrons would be left over to burn the fission products made in this process. This last concept could eventually lead to a new regime of nuclear energy production with minimal requirements for long-term radioactive waste disposal.

\footnotetext{
* Work supported by the US Department of Energy, with Los Alamos National Laboratory Program Development funds.
} 


\section{References}

1. C. M. Van Atta, "A Brief History of the MTA Project," Proceedings of an Information Meeting on Accelerator Breeding, CONF 770107, Brookhaven National Laboratory, Upton, NY, January 18-19, 1977.

2. P. R. Tunnicliffe, B. G. Chidley, and J. S. Fraser, "High Current Proton Linear Accelerators and Nuclear Power", Proceedings of 1976 Proton Linear Accelerator Conf., Chalk River Nuclear Laboratories Report AECL-5677, November 1976, 36-44.

3. M. Steinberg, "Accelerator Spallation Reactors for Breeding Fissile Fuel and Transmuting Fission Products", Nuclear Technologies in a Sustainable Energy System, Eds. G. S. Bauer and A. McDonald, Springer-Verlag, 1983, 203-224.

4. "Accelerator Production of Tritium (APT), Executive Report," Brookhaven National Laboratory Report BNL/NPB-88-143, March 1989.

5. M.T. Wilson, T. S. Bhatia, F. W. Guy, G. H. Neuschaefer, T. P.Wangler, and L. M. Young, "Accelerator for the Production of Tritium (APT)," Proc. 1989 IEEE Particle Accelerator Conf., March 20-23, 1989, Chicago, IL, IEEE Cat. No. 89CH2669-0, 761-763.

6. Accelerator Production of Tritium (APT), A Report of the Energy Research Advisory Board to the United States Department of Energy, February 1990, Department of Energy Report DOE/S-0074.

7. T. P. Wangler, G. P. Lawrence, T. S. Bhatia, J. H. Billen, K. C. D. Chan, R. W. Garnett, F. W. Guy, D. J. Liska, M. R. Shubaly, S. Nath, and G. H. Neuschaefer, "Linear Accelerator for Production of Tritium: Physics Design Challenges," Proceedings of 1990 Linear Accelerator Conf., Albuquerque, NM, September 10-14, 1990, to be published.

8. G. S. Bauer and J. E. Vetter, "The FRG Project for a High-Power Spallation Neutron Source for Fundamental Research," Nuclear Technologies in a Sustainable Energy System, G. S Bauer and A. McDonald, Eds., Springer-Verlag (1983), 237-263.

9. B. Blind, "Generation of a Rectangular Beam Distribution for Irradiation of the APT Target, " Proceedings of 1990 Linear Accelerator Conf., Albuquerque, NM, September 10-14, 1990, to be published.

10. R. W. Gamett, R. S. Mills, and T. P. Wangler, "Beam Dynamics Simulation of the I.AMPF Linear Accelerator," Proceedings of 1990 Linear Accelerator Conf., Albuquerque, NM, September 10-14, 1990, to be published. 
Table I

APT Linac Parameters

$\begin{array}{llll} & \text { RFO } & \text { DTL } & \text { C CL } \\ \text { Frequency (MHz) } & 350 & 350 & 700 \\ \text { Energy (MeV) } & 0.1 \text { to } 2.5 & 2.5 \text { to } 20 & 20 \text { to } 1600 \\ \text { Synchronous phase (deg) } & -90 \text { to }-37 & -40 & -60 \text { to }-40 \\ \text { Radial aperture (cm) } & 0.4 \text { to } 0.3 & 0.8 & 1.4 \text { to } 3.5 \\ \text { Beam current (mA) } & 140 \text { to } 128 & 125 & 250 \\ \text { Length (m) } & 3.4 & 11.3 & 2063 \\ \text { Peak surface field (MV/m) } & 33 & 22 & 7.2 \\ \text { Accelerating gradient }(\mathrm{MV} / \mathrm{m}) & & 1.1 \text { to } 3.1 & 1.0 \text { (lattice avg) } \\ \text { Copper power }(\mathrm{MW}) & 0.4(\times 2) & 1.3(\times 2) & 115 \\ \text { Bcam power (MW) } & 0.3(\times 2) & 2.2(\times 2) & 395 \\ \text { Total power (MW) } & 0.7(\times 2) & 3.5(\times 2) & 510 \\ \text { Beam loading } & 0.43 & 0.56 & 0.78 \\ \text { Number of klystrons } & 1(\times 2) & 5(\times 2) & 470 \\ \text { Accelerating structure } & 4-\mathrm{vane} & 2 \beta \lambda & \text { Side-coupled } \\ \text { Trans. emittance }(\pi \mathrm{mm}-\mathrm{mrad}) & 0.20 \text { to } 0.23 & 0.27 \text { to } 0.58 & 0.61 \text { to } 0.68 \\ \text { Long. emittance }\left(10^{-6} \mathrm{eV} \text {-sec) }\right. & 0.0 \text { to } 1.4 & 1.6 \text { to } 3.0 & 3.0 \text { to } 4.4 \\ & & & \end{array}$




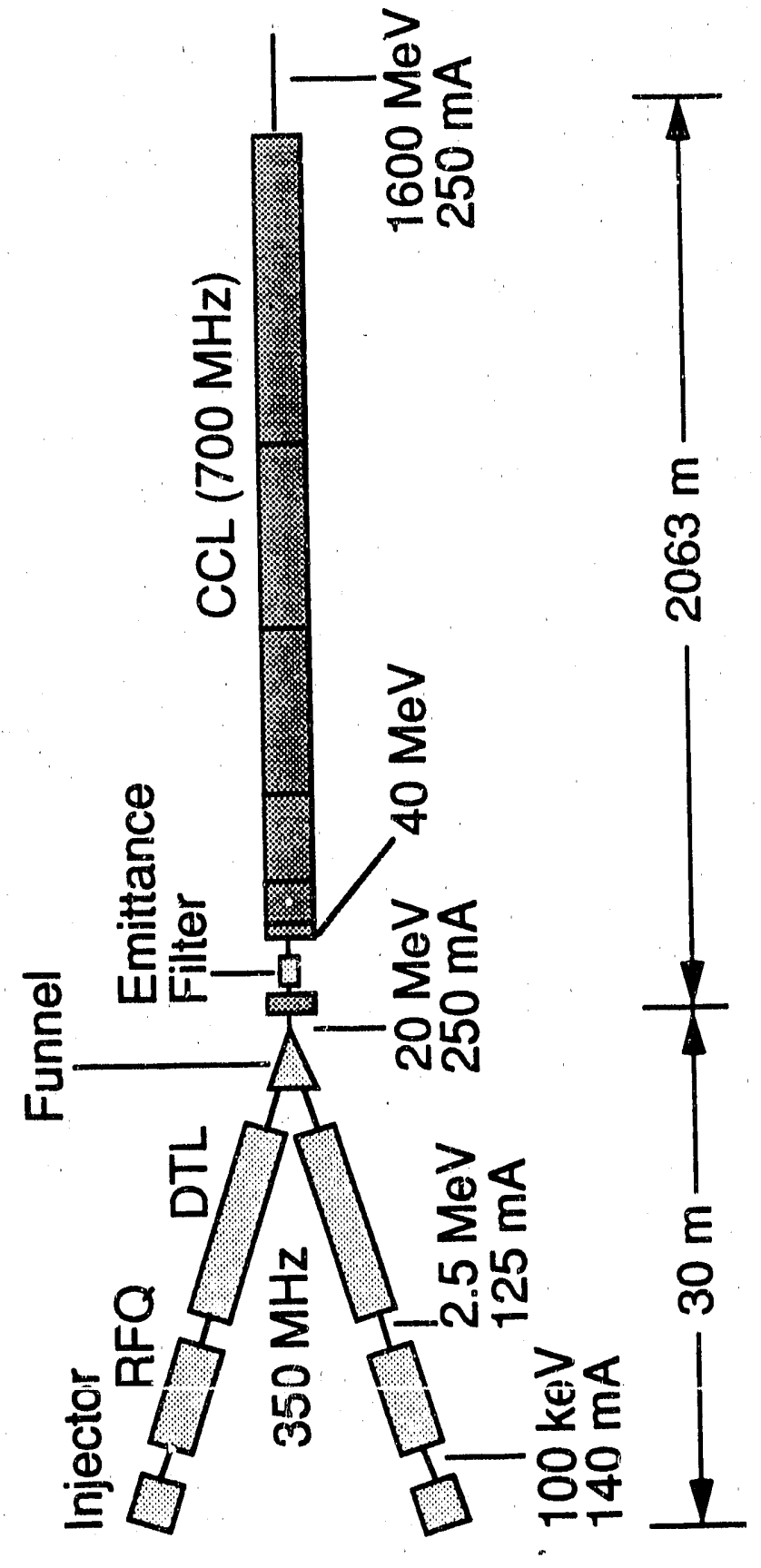




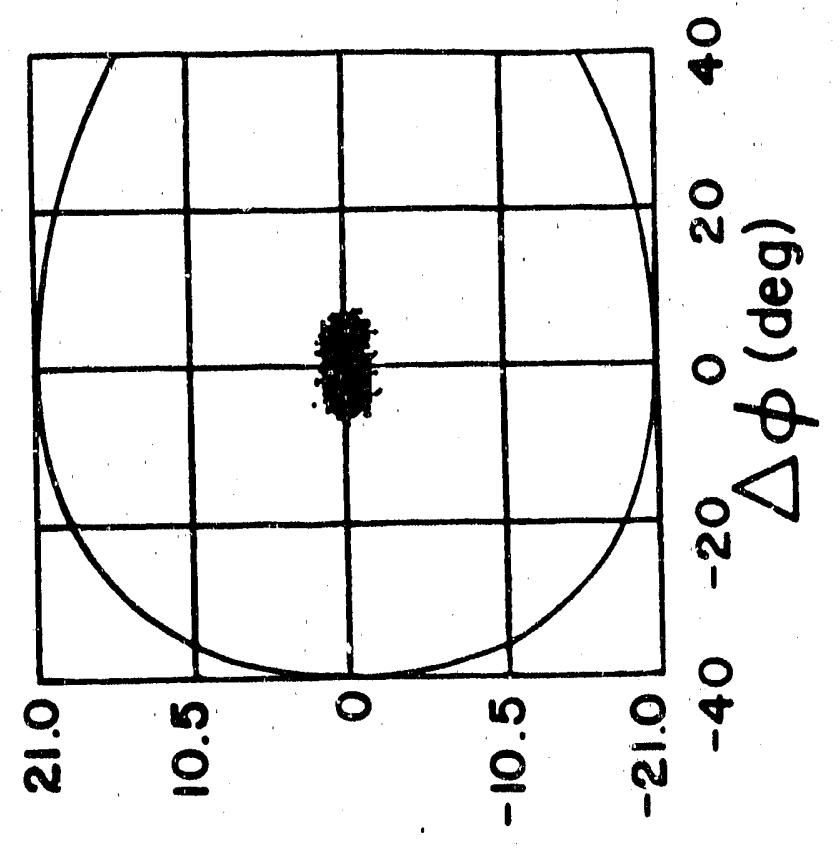

( $\curvearrowright$ W) $M \nabla$

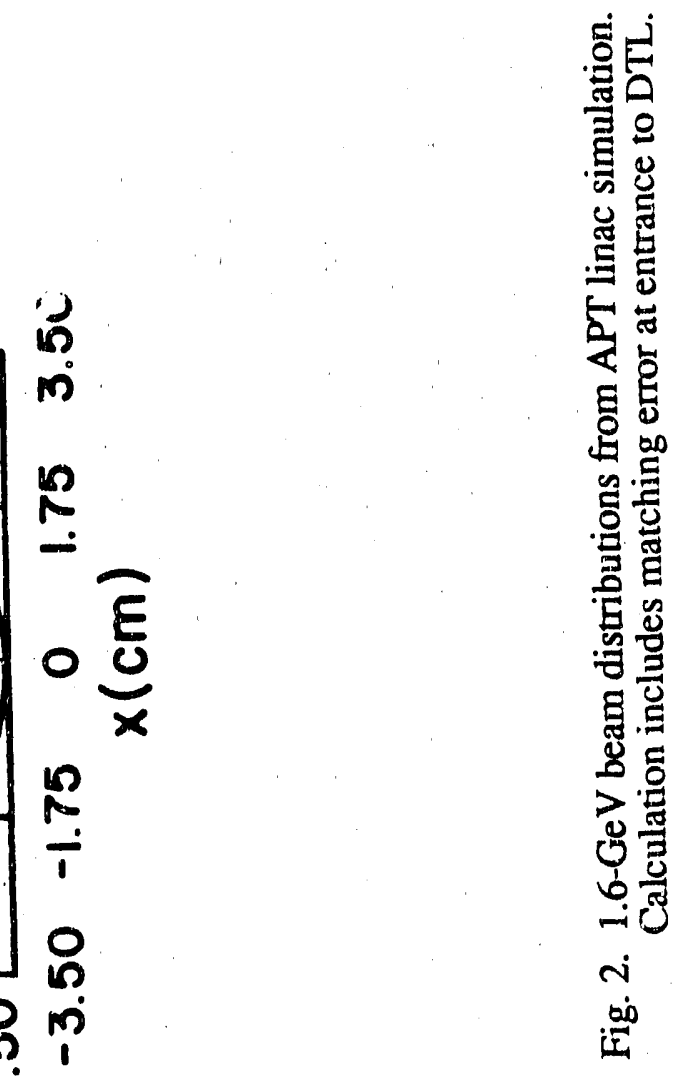

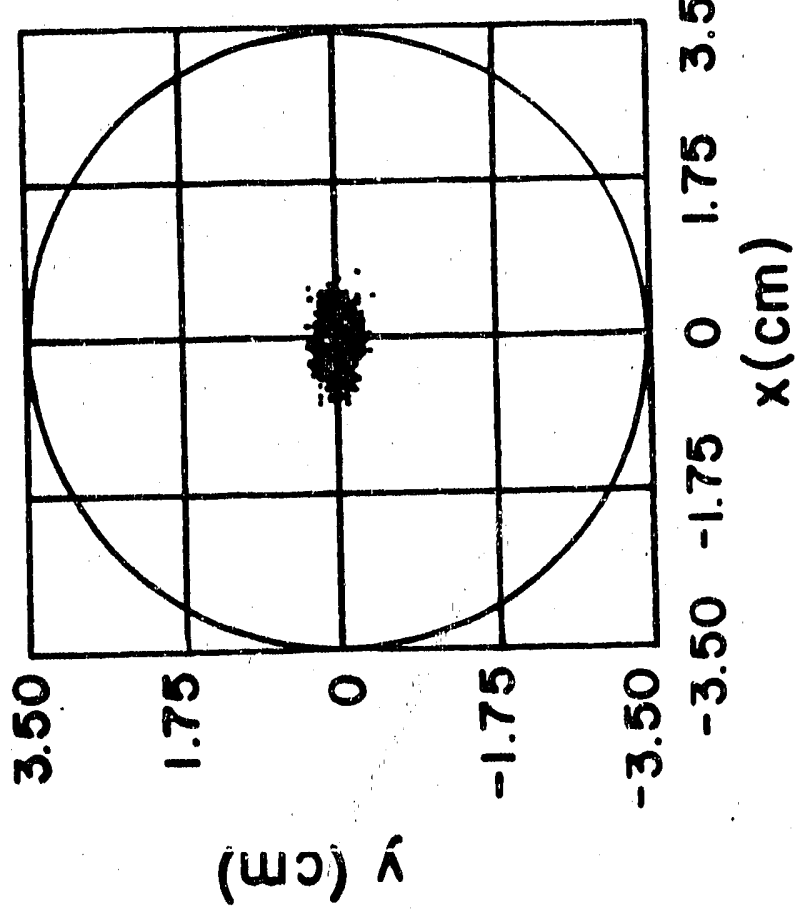




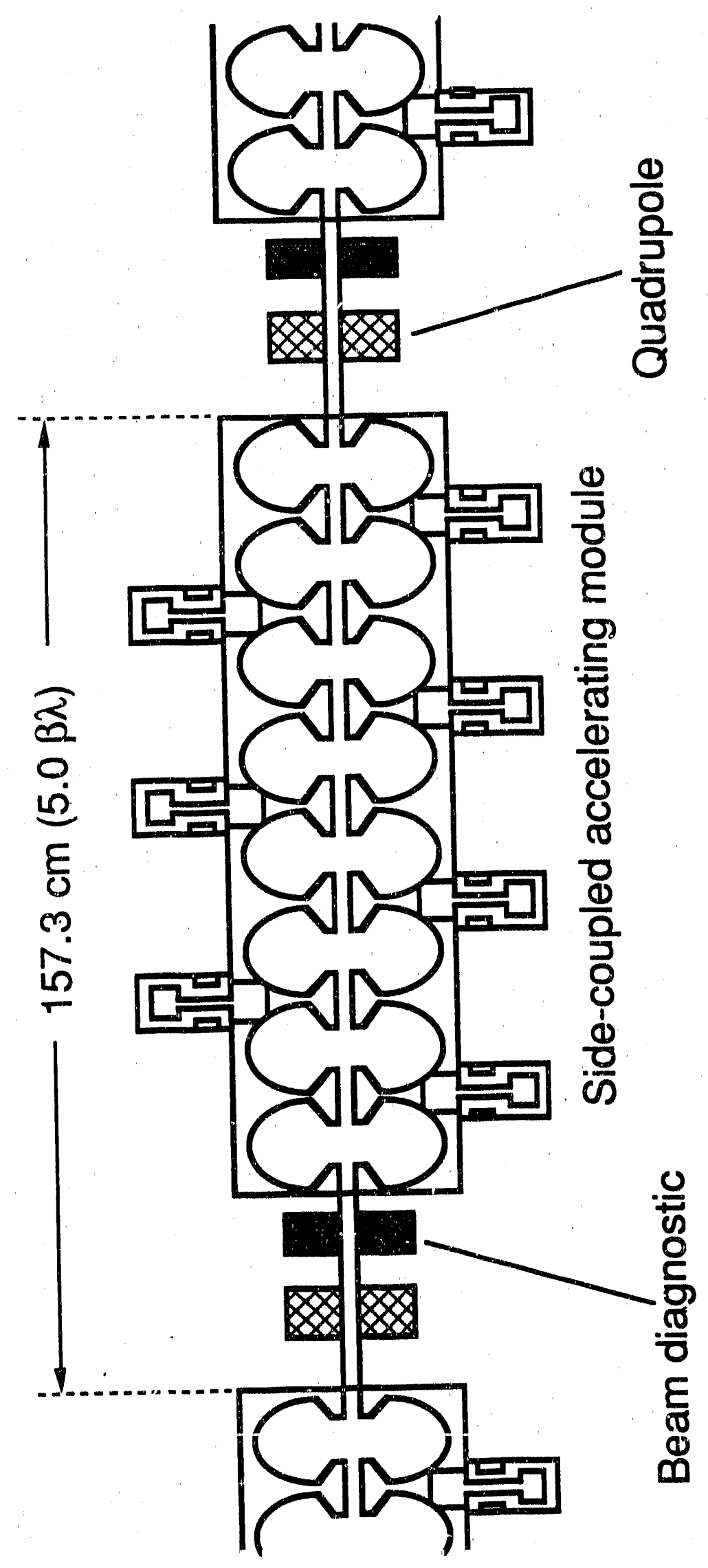

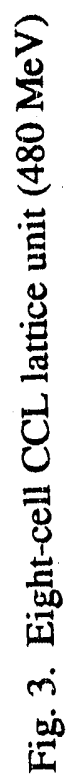




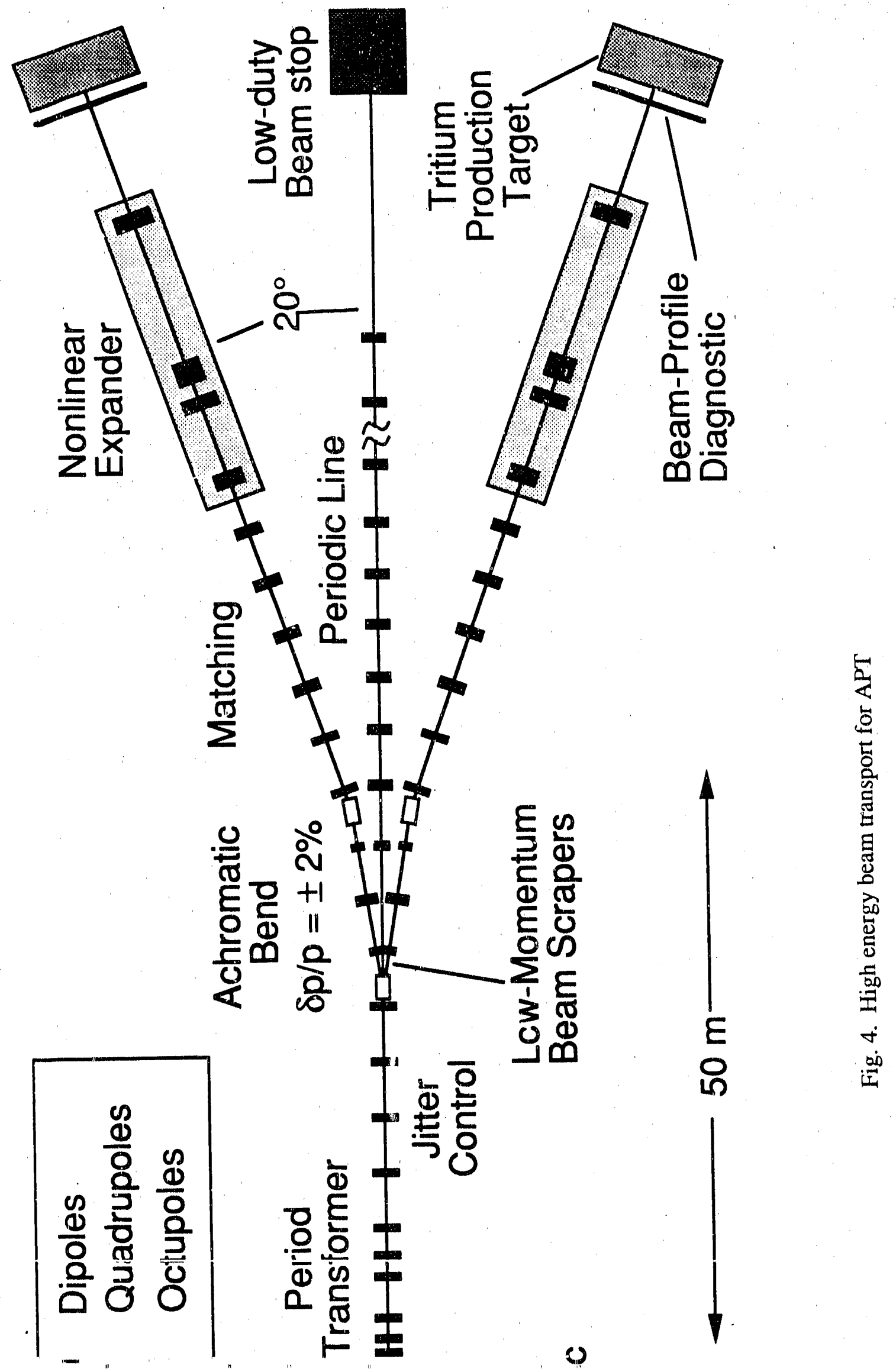




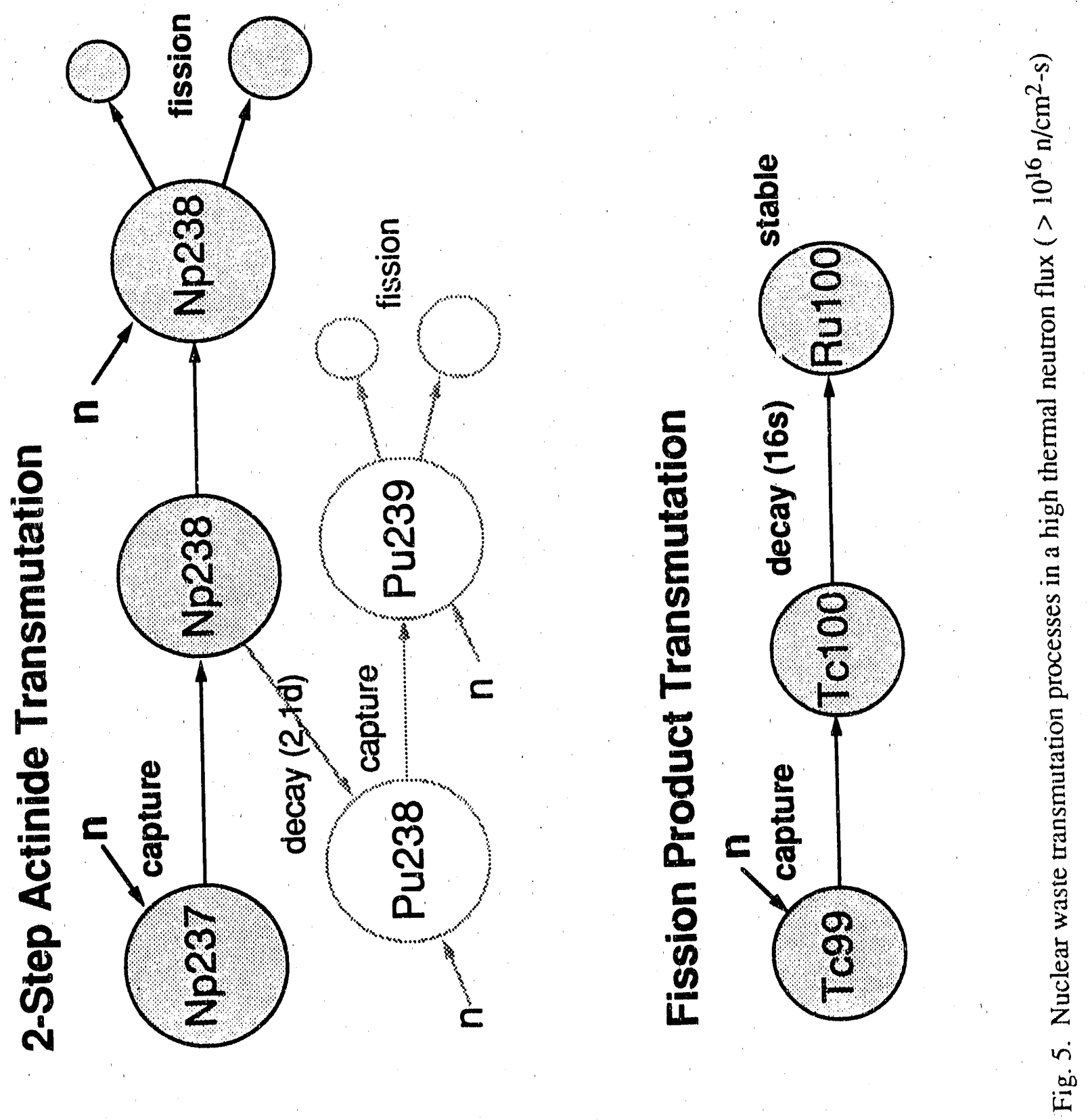



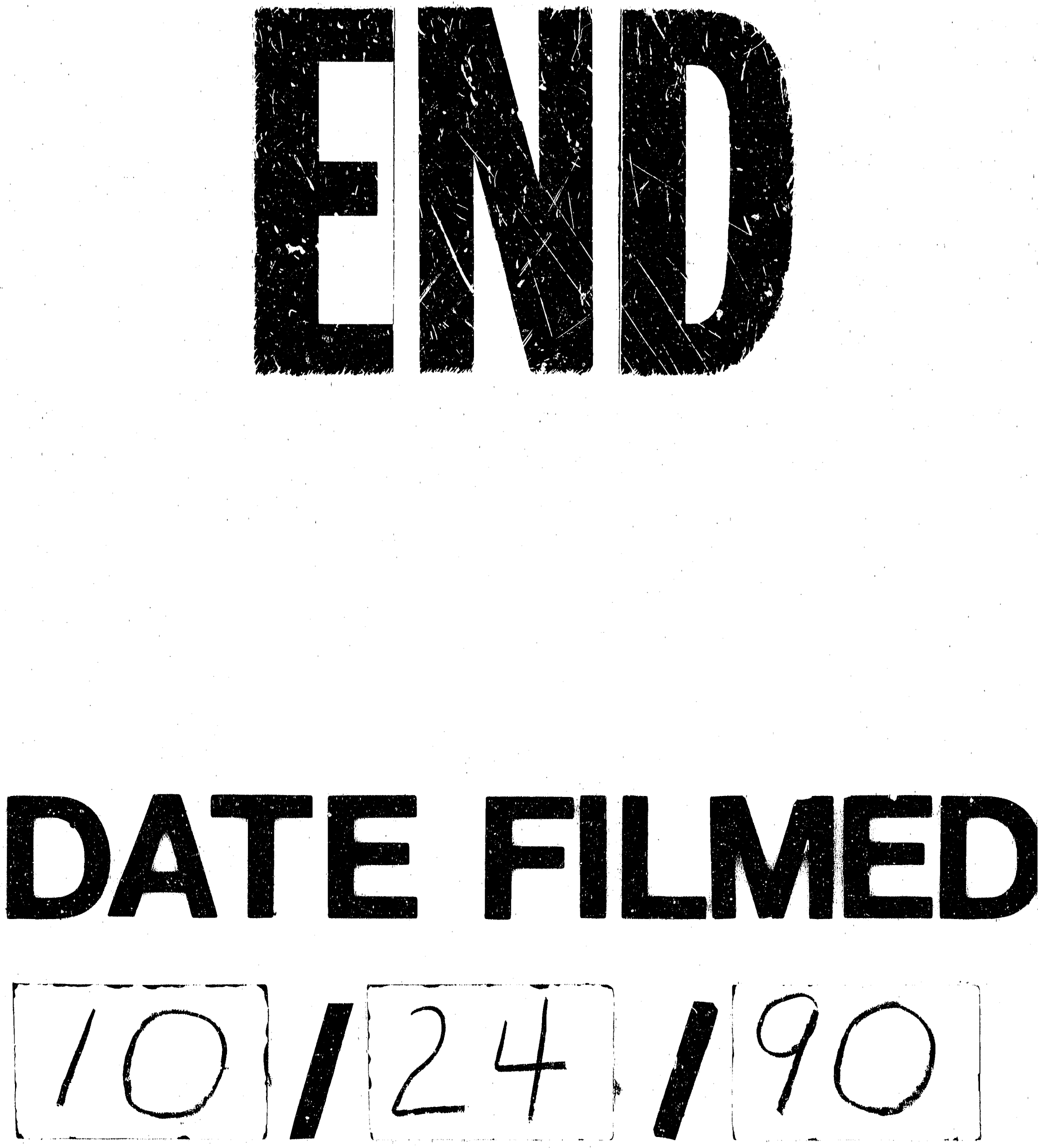


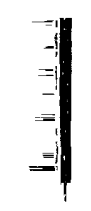

